\title{
La imagen del Otro chino a través de las portadas: un estudio empírico basado en un corpus de traducciones de narrativa china contemporánea al castellano y al catalán (1949-2019)
}

The Chinese Other as reflected in book covers: an empirical study based on a corpus of translations of contemporary Chinese narrative translated into Spanish and Catalan (1949-2019)

TSUN-WEI AN

UNIVERSITAT AUTÒNOMA DE BARCELONA

ORCID: https://orcid.org/0000-0003-0342-7440

RESUMEN: Este trabajo se centra en revelar la imagen del Otro chino que se puede encontrar en las portadas de la narrativa china contemporánea traducidas al castellano y/o al catalán que se publicaron en España desde 1949 hasta 2019. La traducción, desde la antigüedad, ha desempeñado un papel clave en la comunicación entre países y culturas. En este proceso, aparte del texto, los paratextos también se encargan de transmitir información y conocimientos socioculturales de otras literaturas. Además, ofrecen un espacio aún más libre para que los agentes mediadores desplieguen su ideología con el fin de producir una imagen que pueda acercarse más a las expectativas de los lectores receptores. Las 197 portadas recopiladas en nuestro corpus revelan que los paratextos han servido como plataforma valiosa para establecer la imagen del Otro chino en España un tanto distorsionada, ya que, basándonos en un análisis cuantitativo y cualitativo, apreciamos una discordancia temporal entre los modelos chinos que se presentan en las portadas y los que subyacen en el contenido de la obra. Del mismo modo, en este trabajo también encontramos un uso incoherente de los sinogramas en las portadas, que se convierten en una marca cultural con el fin de subrayar el carácter exótico de la cultura china. En definitiva, a través del análisis de las portadas de las traducciones de la narrativa china contemporánea al castellano y al catalán, confirmamos que la imagen de los chinos ha sido parcialmente manipulada, mostrándose un estereotipo estancado en la antigüedad, con un uso 
más predominante del sexo femenino y recurriendo a tópicos exotizantes como la escritura.

Palabras clave: traducción literaria, portadas, paratextos, imagen del Otro, literatura china contemporánea y Orientalismo.

ABSTRACT: The objective of the research is to analyze the images the Other Chinese shows in book covers of contemporary Chinese narrative translated to Spanish and Catalan between 1949 and 2019. In the field of translation, the paratexts can be as important as text itself when delivering cultural information. Nonetheless, the content of paratexts offers more flexibility for the editors and translators to display their own ideology and stereotypes based on the book covers. Having analyzed 197 samples, it is discovered that the image of the Other Chinese in translated book covers make them closer to readers' expects instead of portraying the real image of China. From the viewpoints of the temporality, gender, and the cultural markedness, it is concluded that the translation of paratexts have the tendency of distorting Chinese people in the book covers instead of depicting the theme objectively.

Key words: literary translation, book covers, paratexts, Otherness, Orientalism and contemporary Chinese literature.

\section{INTRODUCCIÓN}

El objetivo principal de este trabajo consiste en analizar la imagen del Otro chino que se muestra en las portadas de traducciones de la narrativa china contemporánea que se publicaron en España a partir de la segunda mitad del siglo XX y tienen el castellano y/o el catalán como lengua de llegada. Nos proponemos examinar, por un lado, si las portadas, en tanto que paratextos, han servido como plataforma para construir la imagen del Otro en la sociedad receptora y, por otro lado, corroborar si la imagen de China que aparece en las portadas de dichas traducciones encaja con el estereotipo que poseen los lectores españoles sobre la cultura china. Ello supondría que la imagen del Otro que aparece en las portadas puede estar manipulada por las editoriales y los traductores, para que se acerque más al perfil y a los conocimientos ya consolidados, que poseen los receptores de otra cultura a lo largo del tiempo.

Los paratextos de cualquier traducción sirven como herramienta valiosa en la construcción de la imagen del Otro, ya que desempeñan un papel insustituible para transmitir información de una cultura a la otra. Además, siendo diferentes del texto que está bajo la influencia del autor, los paratextos ofrecen un espacio más libre a los agentes mediadores para que puedan desplegar su ideología. En este trabajo insistimos en que las portadas pueden constituir un instrumento en la consolidación o reflexión sobre la imagen del Otro chino entre los lectores españoles, a través de la introducción de la literatura china contemporánea traducida al castellano y/o al catalán. Por ello se ha establecido un corpus bien delimitado e integrado en los Estudios de Traducción. Este trabajo se sustenta bajo tres pilares fundamentales desde el punto de vista teórico: los paratextos, el Orientalismo y la imagología, a los que nos referiremos brevemente antes de presentar los resultados del análisis de nuestro corpus. 


\subsection{PARATEXTOS Y PARATRADUCCIÓN}

Las portadas de los libros son uno de los elementos que están al servicio del texto, y a su vez puede ser dividido en subelementos, tales como el prefacio, la reseña, las portadas, las contraportadas y las notas al pie. Genette ([1987] 1997) en su libro Paratexts: Thresholds of Interpretation agrupó estos elementos en el concepto colectivo de "paratextos", afirmando que los paratextos sirven de umbral, el cual se ubica entre el interior y el exterior del texto y ofrecen un espacio a los lectores para que se adentren o se alejen del mismo. De hecho, los paratextos se encargan de transmitir los mensajes, tanto denotativos como connotativos, a los lectores, compensando así la ausencia del contexto compartido entre el sujeto transmisor y el receptor.

A pesar de que Genette ([1987] 1997) investigó los paratextos exclusivamente desde una perspectiva de análisis literario, y sin abordar el área de la traducción, Kovala (1996: 120) consideró vital este vínculo. La traducción, desde la antigüedad, ha tenido y sigue poseyendo un papel clave en la comunicación entre países y culturas, transmitiendo la información y los conocimientos sociales de otras culturas. No obstante, a lo largo de este proceso, tanto lingüístico como cultural, la traducción, antes de presentarse a los lectores de la sociedad de llegada, puede pasar por unos filtros y percibir cierto grado de manipulación de los agentes mediadores (Kovala, 1996). Del mismo modo, el Grupo de Investigación Traducción \& Paratraducción (T\&P) de la Universidad de Vigo propuso el nuevo término "paratraducción" (Yuste Frías, 2005) para relacionar el concepto de paratextos con los Estudios de Traducción, afirmando que, si la traducción traslada e interpreta un texto a otra sociedad, la paratraducción se refiere a una misma actividad que traslada e interpreta los paratextos de una cultura a la otra. Dicho de otro modo, debido al carácter específico de los paratextos que se alejan del texto, la paratraducción no corresponde a una traducción simplemente interlingüística, ni a una actividad neutral, sino que supone a una reescritura, ofreciendo un espacio libre para desplegar la ideología y la manipulación de los agentes de la traducción. Como consecuencia, analizar la paratraducción de un lugar y en un cierto momento nos puede ayudar a discernir la ideología dominante, la estructura del poder y las normas escondidas de aquella sociedad de llegada.

De los diferentes tipos de paratextos, en este trabajo, nos centramos exclusivamente en analizar las portadas, ya que siendo un elemento icónico, las portadas no solo cumplen las funciones de atraer la atención del público, anclar el texto y contribuir a la composición de una imagen social ficticia del mundo conocido (Alvarado, 1994: 28), además, implican la elección del punto de vista para "[reproducir] algunas condiciones de la percepción del objeto, pero después de haberlas seleccionado según códigos de reconocimiento y haberlos registrado según convenciones gráficas (...)” (Eco, 1972: 30, citado en Alvarado, 1994: 28). En cuanto a la traducción, y yendo más lejos, las portadas revelan lo que cree conocer - no lo que se ve- de la sociedad de llegada sobre la cultura original. Es decir, no presentan lo que realmente es la cultura original, sino que reconstruyen una imagen ficticia por la perspectiva subjetiva, adaptándose a lo que los lectores receptores esperan de esa cultura.

\footnotetext{
${ }^{1}$ Nord (2012) mantiene una opinión diferente y afirma que el concepto de "paratraducción" viene de antes, de cuando Genette propuso la teoría de los paratextos en 1987. Aunque el Grupo T\&P de la Universidade de Vigo (Yuste Frías, 2005) acuñó el término de "paratraducción”, Nord considera que es un nuevo nombre creado para un concepto que ya existía en el pasado.
} 


\subsection{CONSTRUCCIÓN DE LA IMAGEN DEL ORIENTE Y EL CONCEPTO DEL OTRO}

Para profundizar en la imagen del Oriente, consideramos imprescindible definir bien el marco geográfico del concepto “Oriente”. Según Said ([1979] 2008), el Oriente, en un principio, se refiere particularmente al mundo árabe, cuya imagen al principio se fue construyendo a través de las batallas y la traducción literaria. No obstante, a partir del siglo XVIII, la situación política de Europa había cambiado mucho y la extensión del colonialismo hizo difuminar el Oriente Medio, India y Asia Oriental (China y Japón). ${ }^{2}$ Desde entonces, Asia Oriental se convirtió por primera vez en un objeto de estudio del Orientalismo. Sin embargo, en el dominio colonial europeo, el choque geográfico, étnico y cultural sugería los conceptos de lo "nuestro" y lo "suyo" entre Europa y Asia Oriental. En esta dicotomía, el mundo occidental nunca concretó la imagen de lo "suyo", sino que inventó la imagen de Oriente a partir de una realidad ficticia con el fin de diferenciar "nuestro territorio" del "territorio de los bárbaros" (Said, [1979] 2008: 87). Además, Said ([1979] 2008) también constató el poder del sexo en las dos culturas, afirmando que los occidentalistas suelen presentarse como figuras masculinas en sus textos, en cambio, en cuanto a los papeles relacionados con Oriente, los designan con imágenes femeninas. En este sentido, si bien Asia Oriental ya había aparecido en la escena mundial, todavía no se había mostrado con su perfil real, sino que seguía siendo descrito con un estilo occidental, que pretendía dominar, reestructurar y tener autoridad sobre ella (Said, [1979] 2008: 21). En otras palabras, desde la Ilíada hasta las Cruzadas, Oriente nunca fue bien comprendido, pero sí bien imaginado: lo exótico, lo misterioso o lo sensual eran conceptos contrarios al perfil de Occidente: fuertes, rubios, razonables o civilizados.

Carbonell (2004) ahondó el concepto del Otro con cuatro enfoques, tal como se muestra en la figura 1.

a) El campo del Mismo (identificación): en este campo, los lectores se sitúan en una sensación que les rodea sin diferencia alguna de su propia cultura. No obstante, en la realidad no existen dos culturas totalmente iguales y, por lo tanto, es imposible ubicarnos en una cultura de la identificación del "Mismo".

b) El campo del Otro (alteridad): lo que conciben los lectores es totalmente diferente a su propia cultura. Se corresponde a los métodos de traducción que tienden a crear un ambiente ajeno y con una distancia cultural insalvable. Sin embargo, la constitución de la alteridad absoluta es inalcanzable, ya que los lectores siempre comparten alguna afinidad a partir de los conocimientos o experiencias del ser humano.

c) El campo del "no-mismo" (extrañamiento): en este campo, los lectores identifican las experiencias nuevas como extrañas. Para crear un ambiente exotizante en la traducción, se suelen utilizar "calcos léxicos y sintácticos, tipografías y sonidos ajenos, organizaciones discursivas y retóricas inusuales, ilustraciones exóticas y otros paratextos, recursos todos ellos caracterizados por rasgos estereotipados que apuntan, sí, a una «visibilidad»" (Carbonell, 2004: 68). En cuanto a la traducción de los paratextos, se puede crear un ambiente exótico que no existe en el texto original, además de construirse una imagen estereotipada en la sociedad de llegada.

\footnotetext{
2 En la traducción al castellano, Orientalismo (2008), se utiliza el término "Lejano Oriente" para referirse a lo que Said (1979: 1) llamó "Far East (China and Japan, mainly)". Sin embargo, lo hemos sustituido por el término "Asia Oriental" al ser este actualmente el de uso común en la academia española.
} 
d) El campo del "no-otro" (familiarización): ofrece la posibilidad de puente entre culturas a los lectores para que identifiquen las cosas mentalmente ajenas como conocidas.

\section{Figura 1. La construcción del Otro adoptada por Carbonell (2004: 66)}

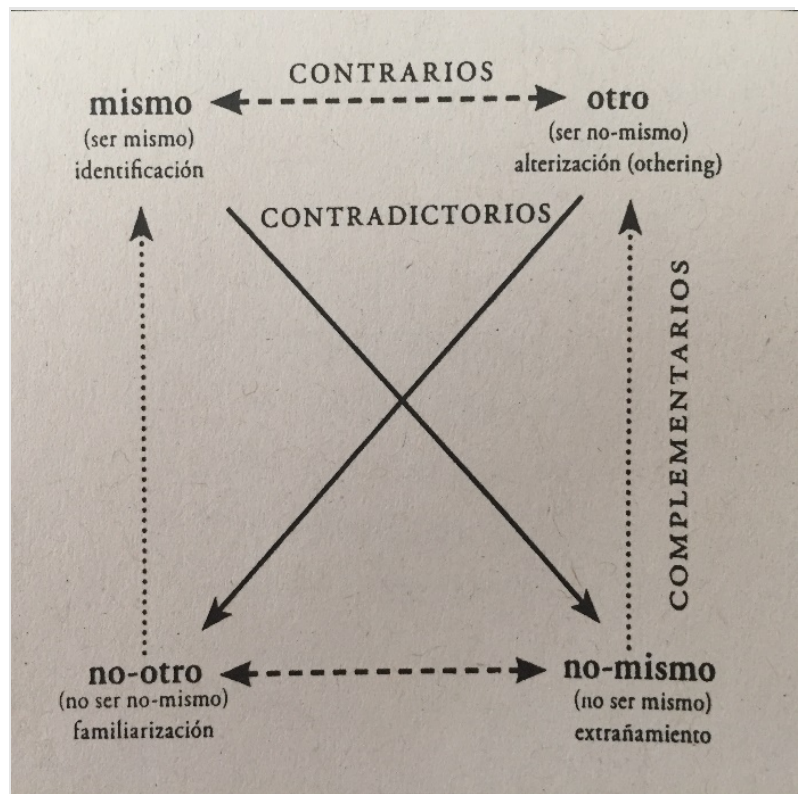

Según la propuesta de Carbonell (2004), observamos que la absoluta identificación propia y la alteridad total son imposibles de establecer, ya que no existe información que venga completamente de dentro o de fuera de la experiencia propia. En este sentido, el concepto del Otro en la traducción se acerca más al campo del "no-mismo", es decir, no proviene de una alteridad absoluta. De hecho, cuando dos culturas se ponen en contacto, se produce un vacío de información y la traducción juega un papel destacado en este vacío con el uso deliberado de recursos, tales como el léxico, el formato, las ilustraciones, las portadas, las contraportadas y otros paratextos. Así, cualquier nivel diferencial puede convertirse en signo del "no-mismo" y construir la imagen del "Otro" en la traducción. Del mismo modo, Beller y Leersen (2007) afirmó que la imagen del Otro se refiere a las características parciales que tenemos sobre otros grupos, tribus o razas lejanas. Es decir, la discontinuidad y las diferencias culturales provocan la percepción selectiva y restringen la perspectiva de conocer otra cultura. Desde esta perspectiva, una información mínima presenta el valor máximo, la parte representa el conjunto y produce el estereotipo del Otro. Además, una vez establecido, el estereotipo se resiste al cambio.

\subsection{IMAGOLOGÍA Y LOS ESTUDIOS DE TRADUCCIÓN}

La imagología es una disciplina que estudia la justificación unilateral que tiene uno con otros países, grupos, sociedades o culturas (Soenen, 1992: 128). Al abordar la literatura, la imagología profundiza en el origen, la formación y la función de las características mostradas en la literatura con el objetivo de revelar los prejuicios y estereotipos que se tengan sobre "ellos" (Beller y Leersen, 2007: 8).

Soenen (1992) ahondó en la integración de la imagología y los Estudios de Traducción, centrándose en cómo y hasta qué nivel la imagen estereotipada de otros países y culturas influye en la producción de la traducción. Por ejemplo, Dyserinck (1977, citado en Soenen, 1992: 129) subrayó el papel de "la creación de la imagen" (imagebildung) en la 
literatura traducida en los años 70, afirmando que la presentación de las obras o los autores preferentes en traducción se adapta a la imagen que tienen los lectores sobre aquellos países o culturas, y, además, pretende ajustarse a las expectativas de los lectores de llegada. En este sentido, las obras y los autores que no encajan en la imagen del Otro casi no se traducen en la sociedad de llegada.

Del mismo modo, Venuti (1998: 67) afirmó que en los Estudios de Traducción, "la imagen" indica el perfil de las obras traducidas que se refleja en la sociedad de llegada. En este proceso, la traducción adquiere mucho poder al describir otra cultura, pero suele presentar un aspecto parcial de la cultura extranjera y sustituir lo exótico al conjunto. Así, se dirige la discontinuidad hacia la desfiguración de la cultura y produce la imagen del Otro en la sociedad de llegada (Carbonell, 2004).

\section{CORPUS}

Para investigar la imagen del Otro chino en las portadas que se refleja en la sociedad española a través de las traducciones de narrativa china contemporánea, hemos adoptado los cuatro elementos básicos que propuso Fernandes (2006: 88) para establecer un corpus bien delimitado relacionado con los Estudios de Traducción. Según los parámetros de representatividad, tamaño, formato electrónico y carácter abierto, hemos forjado un corpus finito, diacrónico, específico con micro-nivel y, asimismo, de formato electrónico y multi-modal (incluyendo la imagen como fuente semiótica). Es decir, hemos recopilado las traducciones de la narrativa china contemporánea que se publicaron en el territorio español entre 1949 y 2019 y que, además, todas tienen el castellano y/o el catalán como lengua de llegada.

Aparte del lugar y el año de publicación de las traducciones, hemos tomado nota del género literario y las lenguas de trabajo. En primer lugar, consideramos importante definir con precisión los diferentes términos usados dentro del género de la narrativa en la cultura china y la española. En este trabajo se incluyen, pues, changpian xiaoshuo (長篇小說), duanpian xiaoshuo (短篇小說) y sanwen (散文), que se corresponden en cierto modo a los términos de novela, relato corto y prosa en castellano, respectivamente.

En segundo lugar, nos parece importante definir bien los conceptos de literatura china, literatura sinófona y literatura sinoextranjera. Marin-Lacarta (2012: 42 y 146) propuso que literatura china quedara definida como las obras escritas en chino, producidas dentro de los límites geográficos de la República Popular China. Por otro lado, literatura sinófona se refiere a las obras escritas en chino como lengua original de las comunidades chinas en el extranjero. En este marco referencial, Shih Shu-Mei (2004: 29; 2011: 710 y 717) amplía el concepto de sinófono, refiriéndose al que tiene el idioma chino como lengua materna, pero sin identificarlo con el patrón geopolítico de gobernanza de la República Popular China. Dicho de otra manera, el término sinófono esboza una nueva interpretación de la comunidad lingüística y literaria china, que tiene al idioma chino como lengua materna, pero que no se identifica geográficamente con el estado chino.

Por otro lado, el concepto de literatura sinoextranjera que propuso Marin-Lacarta (2012: 134-136) es el menos ambiguo. La literatura sinoextranjera corresponde a obras escritas en otros idiomas diferentes al chino por autores de origen chino. A modo de ejemplo, no hemos incluido Amy Tan en el corpus, a pesar de que sus obras se dedican a explorar la sociedad china moderna y algunas han sido traducidas al castellano, tales como El club de la buena estrella (1997) y La esposa del dios del fuego (1992), pero todas tienen el inglés como lengua de partida y como resultado no encajan en nuestro criterio de selección. En consecuencia, en este corpus nos centramos concretamente en 
recopilar las obras de la literatura china y sinófona como objeto de análisis, excluyendo las obras que pertenecen a la literatura sinoextranjera.

Por último, subrayamos que en este corpus delimitamos exclusivamente las obras originales escritas en chino moderno (baihua), ya que a partir del Movimiento del 4 de Mayo en 1919, el uso del chino clásico (wenyan) fue restringido a la literatura clásica. En cambio, el chino moderno se convirtió en símbolo de la literatura contemporánea de China. En este contexto histórico y con el objetivo de revelar la imagen del Otro chino a través de la literatura china contemporánea, solo recopilamos las traducciones de las obras de narrativa de la literatura contemporánea, excluyendo las de la literatura clásica escrita en el chino wenyan. Es decir, la variante de chino baihua también constituye un parámetro indispensable de delimitación del corpus.

En consecuencia, según los diferentes parámetros para definir la lengua de partida y de llegada, el género literario y el lugar de publicación, creamos una base de datos a partir de nueve plataformas como fuente de nuestro corpus:

a) Index Translationum ${ }^{3}$

b) Catálogo Colectivo de las Universidades Catalanas (CCUC)

c) Biblioteca Nacional de España

d) Catálogo de la Red de Bibliotecas Municipales de Catalunya

e) Catálogos de librerías

f) China traducida y por traducir ${ }^{4}$

g) Base de datos de libros editados en España ${ }^{5}$

h) Grupo de investigación en Traducción del chino al catalán/castellano (TXICC) ${ }^{6}$

i) Editoriales

Gracias a todas estas fuentes, finalmente recopilamos un corpus formado por 158 traducciones en castellano y/o en catalán. Estas traducciones corresponden a 197 ediciones publicadas en España, cada una con su propio ISBN y en muchos casos paratextos diferentes. En otras palabras, las reimpresiones no se tienen en cuenta, ya que no tienen ISBN propio.

\section{METODOLOGÍA}

Con el objetivo de analizar con precisión las portadas de las traducciones de la narrativa china contemporánea recopilada en nuestro corpus, destacamos el concepto de la variable que propuso Bell (2000) como metodología. Según Bell (2000: 15), las variables se refieren a los parámetros que pueden definir exclusiva y exhaustivamente una categoría de otra. Asimismo, Bell (2000: 17) nos dio ejemplo de cuatro variables para clasificar y analizar las imágenes visuales: gender, role, setting y size. Basándose en este concepto, Serra-Vilella (2018: 146) propuso tres variables para clasificar y analizar las portadas de las novelas japonesas traducidas en España: cultural markedness, temporality

\footnotetext{
${ }^{3}$ Página web de Index Translationum: < http://www.unesco.org/xtrans/bsform.aspx > [consultado en abril de 2020].

${ }^{4}$ Página web de "China traducida y por traducir": < http://china-traducida.net/> [consultado en abril de 2020].

${ }^{5}$ Página web de "Base de datos de libros editados en España":

$<$ https://www.culturaydeporte.gob.es/cultura/libro/bases-de-datos-del-isbn.html $>$ [consultado en abril de 2020].

${ }^{6}$ Página web de "Grupo de investigación en Traducción del chino al catalán/castellano":

$<$ https://dtieao.uab.cat/txicc/lite/> [consultado en mayo de 2020].
} 
y main represented element. Según Serra-Vilella, cultural markedness se refiere a los elementos que sirven para identificar el carácter oriental con claridad y temporality corresponde a los elementos presentados en la imagen que pueden representar cierta época.

Teniendo en cuenta el objetivo de nuestro análisis, en este trabajo aplicamos las variables que utilizan Bell y Serra-Vilella y proponemos tres variables para analizar las 197 portadas recopiladas en nuestro corpus: la temporalidad, el sexo y la marca cultural (los sinogramas).

Respecto a la temporalidad, la dividimos en tres períodos y dos tipos específicos desde el punto de vista temporal:

a) Época tradicional (antes de 1949): se refiere al período transcurrido antes de que se fundara la República Popular China en 1949, el año que marca el inicio de la historia moderna de China.

b) Época comunista (1949-1989): corresponde al período en el que China estuvo bajo el mandato más revolucionario del comunismo maoísta, que incluye los movimientos del Gran Salto Adelante, la Revolución Cultural hasta las protestas de la Plaza de Tian'anmen.

c) Época de apertura (1990-2019): se inicia a finales de los años 80 cuando China puso fin a las políticas revolucionarias y empezó una serie de reformas económicas y cambios sociales.

d) Portadas con imágenes sin referencias o especificaciones a ningún momento histórico concreto, que hemos etiquetado como atemporales.

e) Aparte de las portadas que son susceptibles de ser clasificadas desde el punto de vista temporal, encontramos el tipo de portada simple que no incluye ninguna imagen.

En cuanto al sexo, lo dividimos en tres categorías: hombre, mujer y otros. Otros se refiere a aquellas portadas en las que la imagen incluye tanto hombres como mujeres, o aquellos casos en los que no podemos distinguir su sexo, tal como se muestra en la figura 2. Por último, consideramos que los sinogramas constituyen uno de los símbolos de la cultura china y a menudo funcionan como reclamo estético. En este sentido, utilizamos los sinogramas como la variable de marca cultural para identificar y analizar este aspecto de las portadas.

Figura 2. Portadas con figuras humanas del tipo "otros"
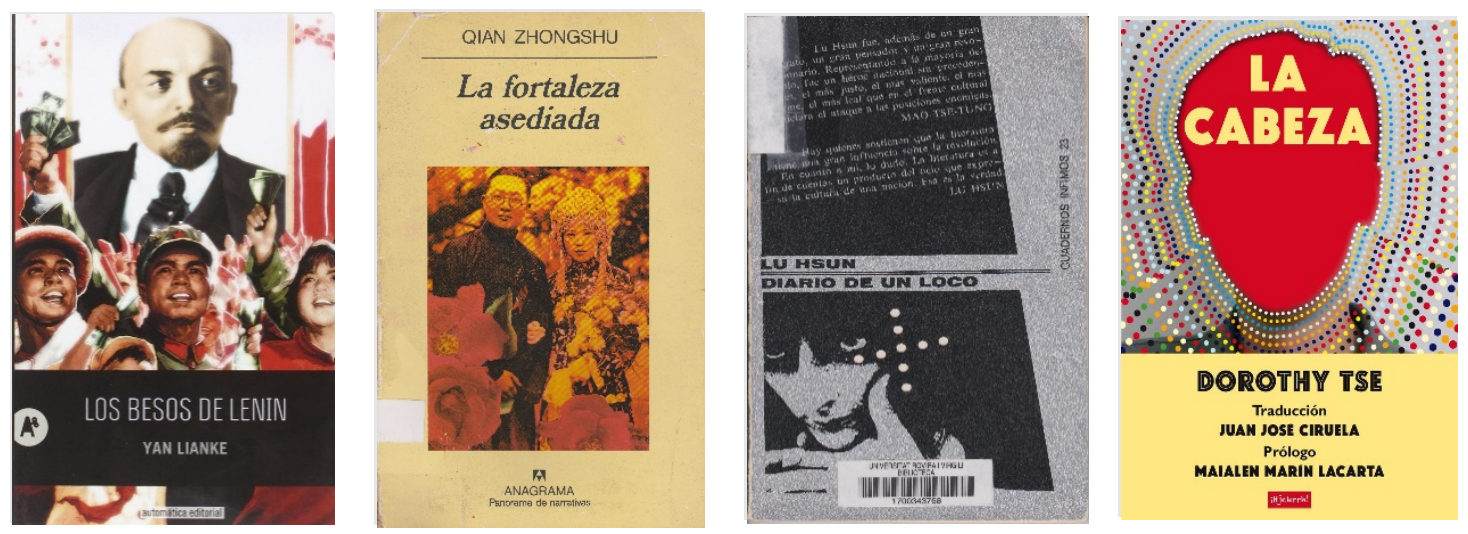


\section{ANÁLISIS DE PORTADAS}

En este apartado, analizamos las portadas según los tres parámetros mencionados: la temporalidad, el sexo y las marcas culturales. En el subapartado 4.1, nos hemos centrado en la temporalidad que evocan las imágenes de las 197 portadas recopiladas en nuestro corpus, con el objetivo de averiguar si existe una selección preferente en presentar la imagen de China con cierto ambiente temporal que funciona como estereotipo o metáfora de China. En el subapartado 4.2, se ha profundizado en las figuras humanas que aparecen en las portadas y las hemos analizado según las variables de sexo y temporalidad, para corroborar si Oriente ha sido y sigue siendo presentado de una forma contraria al perfil fuerte y masculino de Occidente, con una imagen más sensual y femenina (Said ([1979] 2008: 21). En el subapartado 4.3, repasamos el uso de los sinogramas en las portadas, en tanto que aspecto característico de la cultura china, para revelar si se ha recurrido a esta marca cultural para introducir la cultura china o se ha convertido en instrumento para fortalecer la imagen exótica del Otro chino.

\subsection{TEMPORALIDAD}

En este subapartado, examinamos el ambiente temporal que transmiten las portadas a través de la variable de la temporalidad. Del mismo modo, la dividimos en tres épocas y dos tipos específicos según el desarrollo histórico de China: época tradicional (antes de 1949), época comunista (1949-1989), época de apertura (1990-2019), la categoría atemporal y la portada simple. A través de este análisis, nos disponemos a advertir si la imagen de los chinos ha quedado estancada en una época determinada que funciona como estereotipo y metonimia de China, a pesar del desarrollo histórico y de un mayor conocimiento mutuo entre España y China.

De las 197 portadas recopiladas en nuestro corpus, encontramos un $8 \%$ que pertenecen al tipo simple, un 39\% a la época tradicional, un $9 \%$ a la comunista, un $26 \%$ a la época de apertura y un $18 \%$ presentan imágenes atemporales. Es decir, la mayoría de las imágenes que se han adoptado como portadas corresponden a la época tradicional, mientras que la época de apertura representa un cuarto del total. Por otro lado, hemos contrastado estos resultados con el contenido de la obra y nuestro análisis demuestra que se recurre a la época tradicional como metonimia de la imagen de China en la sociedad española, de modo que las editoriales escogen este tipo de portadas también para representar las historias comunistas y modernas de China. En definitiva, a través de la figura 3, observamos que existe un $32 \%$ de casos en los hechos narrados en las obras no coinciden con sus respectivas portadas. Dicho de otro modo, no existe una coherencia entre la imagen y la época en la que transcurre la trama. En este sentido, consideramos necesario profundizar con más detalle en esta cuestión. 
Figura 3. Tipos de portada según la temporalidad

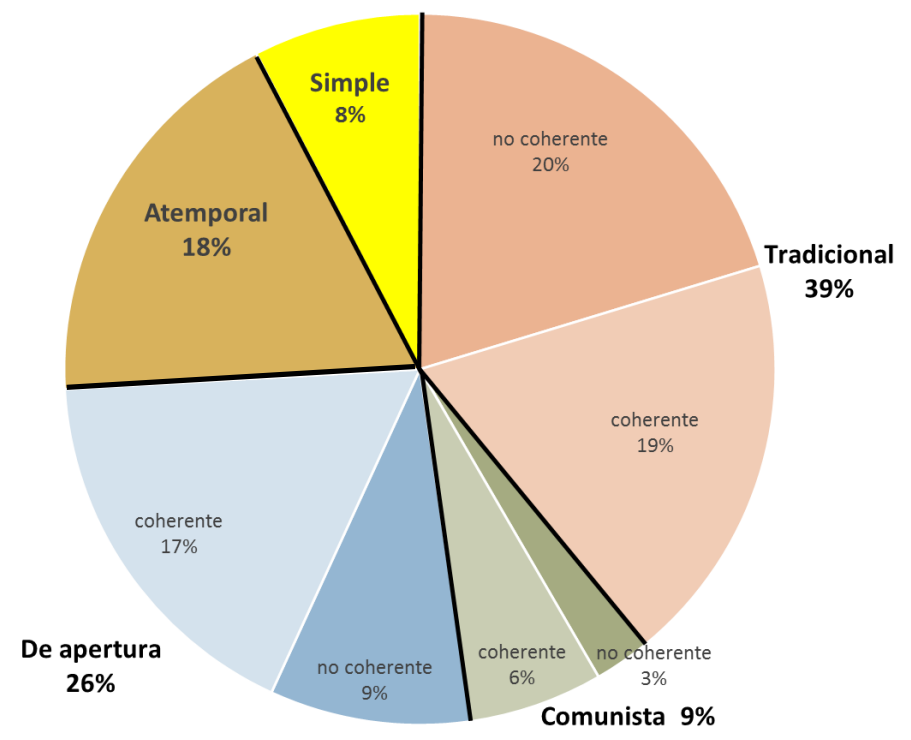

Tal como muestra la tabla 1, observamos que cuando una obra está ambientada en la época tradicional, la mayoría de las imágenes de las portadas coinciden con la mencionada época, llegando a más de la mitad del total de los casos. Por el contrario, los resultados de nuestro análisis ponen de manifiesto que las obras del período comunista generalmente han sido presentadas con una imagen atemporal o con portadas de la época tradicional. Es decir, no se muestra una vinculación coherente entre el contenido y la portada. Además, cuando ahondamos en las 36 portadas atemporales para ilustrar una trama narrativa ambientada en la época comunista, 29 de ellas no han desvelado la huella del comunismo y las tres restantes pertenecen a imágenes neutrales, tal como se muestra en los ejemplos de la figura 4.

Tabla 1. Época relativa al contenido y la mostrada en portada

\begin{tabular}{ccccccc} 
Contenido & \multicolumn{7}{c}{ Portada } \\
& Tradicional & Comunista & De apertura & Atemporal & Simple \\
Tradicional & $\mathbf{3 7}$ & 3 & 5 & 3 & 9 \\
Comunista & $\mathbf{2 6}$ & 12 & 12 & $\mathbf{2 9}$ & 0 \\
De apertura & 14 & 2 & $\mathbf{3 3}$ & 3 & 0 \\
Sobre Taiwán & 0 & 0 & 2 & 1 & $\mathbf{6}$ \\
\hline \hline Total & 77 & 17 & 52 & 36 & 15
\end{tabular}


Figura 4. Portadas que recurren a imágenes atemporales sin relación con el contenido de la historia de trasfondo comunista
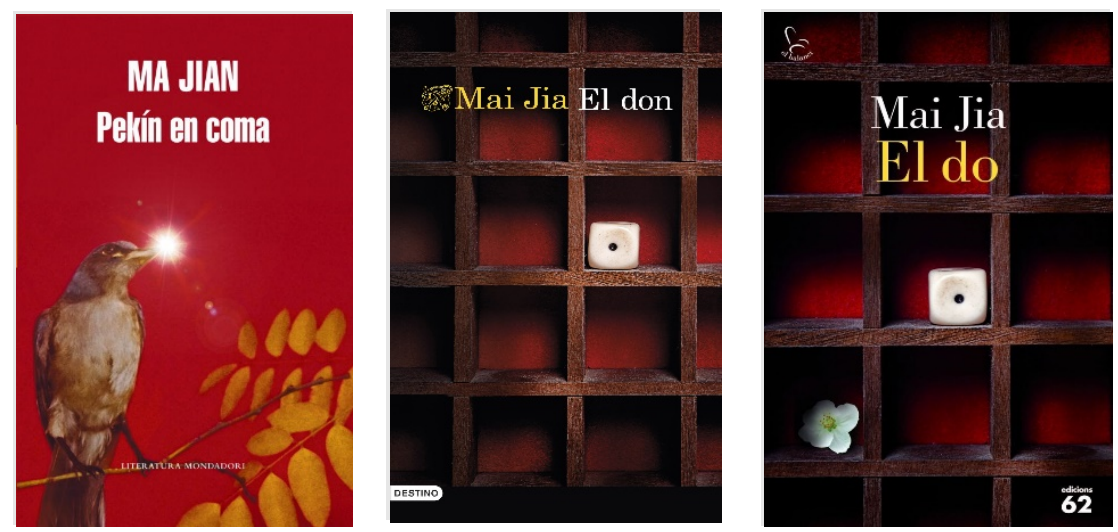

Respecto a las obras ambientadas en la época de apertura, apreciamos que la mayoría de imágenes muestran una coherencia con su contexto histórico, dejando una nueva imagen moderna de la cultura china a los lectores españoles. Es decir, las editoriales han escogido la época tradicional como metonimia principal de la imagen de China, aunque también han intentado mostrar una cara moderna de los chinos en la sociedad española. Sin embargo, el trasfondo comunista ha seguido siendo escondido en este proceso, debido a que encontramos 93 de 133 obras traducidas al castellano y/o al catalán que cuentan una historia de la época comunista, pero el resultado del análisis de la temporalidad de las imágenes no concuerda con el número de las historias que ambientan su trama en el comunismo. En consecuencia, podemos concluir que las editoriales mediadoras que se encargan de introducir la literatura china en la sociedad española, tienden a escoger la imagen tradicional y moderna como metonimia de la cultura china, además, pretenden disimular la huella del comunismo, a pesar de que el carácter comunista ha sido una base importante y firme en la producción de la literatura china contemporánea.

\subsection{FIGURAS HUMANAS}

Con el objetivo de estudiar la imagen del Otro chino a partir de las imágenes que aparecen en los paratextos de las traducciones de narrativa china contemporánea, consideramos necesario profundizar más en las figuras humanas que aparecen en las portadas. De las 197 publicaciones recopiladas en nuestro corpus, encontramos 99 que contienen figuras humanas como elemento de portada, clasificadas en tres tipos según el sexo: hombre, mujer y otros.

De las 99 portadas que contienen figuras humanas en nuestro corpus, encontramos que el sexo predominante es el de mujer, con un 55\% de los casos, tal como muestra la figura 5. En cambio, las de hombre y la categoría otros ocupan un 32\% y 13\%, respectivamente. Es decir, en los casos en los que se ha optado por presentar la imagen de la cultura china con figuras humanas, las editoriales han escogido preferentemente a la mujer china como representante. 
Figura 5. Proporción del sexo de las figuras humanas de las portadas

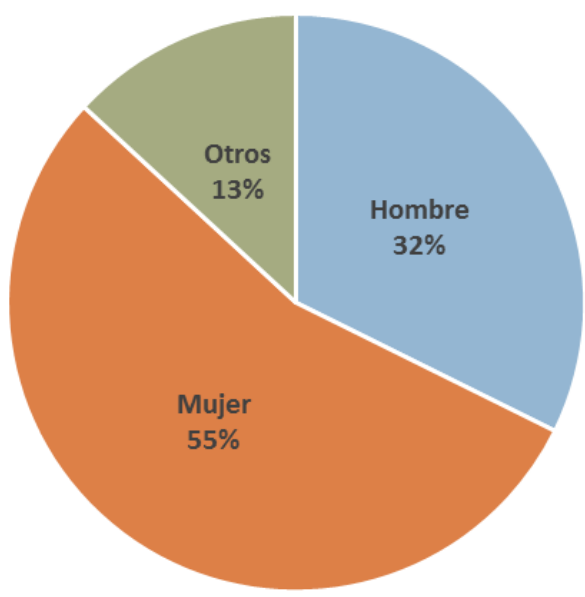

\subsubsection{Figuras humanas con la temporalidad}

Si analizamos la temporalidad con los tres tipos de figuras humanas: hombre, mujer y otros, obtenemos la figura 6. En ella advertimos que, en primer lugar, de las 99 portadas con figuras humanas, las de la época tradicional ocupan un 39\% de los casos y las de la época de apertura un 36\%. En cambio, las de la época comunista y atemporal solo llegan a un $13 \%$ y un $12 \%$, respectivamente. Dicho de otro modo, con el análisis de las figuras humanas, constatamos de nuevo que las editoriales se inclinan por presentar la sociedad china con una imagen tradicional y moderna a los lectores españoles, mientras que, en números absolutos, las obras ambientadas en la época comunista de China son, en realidad, las más abundantes, tal como se observaba en la tabla 1.

En segundo lugar, si profundizamos en el análisis del sexo en relación con la temporalidad, apreciamos que, en cuanto a la época tradicional, no se distinguen muchas diferencias entre el uso del hombre y de la mujer. Sin embargo, destaca la presencia visible de las mujeres en las imágenes correspondientes a la época de apertura y las atemporales. Por otro lado, el hombre ha sido sobre todo representante de la época comunista, pero no tanto con un perfil atemporal. En consecuencia, a pesar de que el número de figuras humanas ha sido el predominante en la época tradicional, en este período no se aprecian diferencias entre los dos sexos. Por el contrario, la mujer adquiere relevancia en la época de apertura y también con las imágenes atemporales.

Figura 6. Porcentaje de figuras humanas en relación con la temporalidad
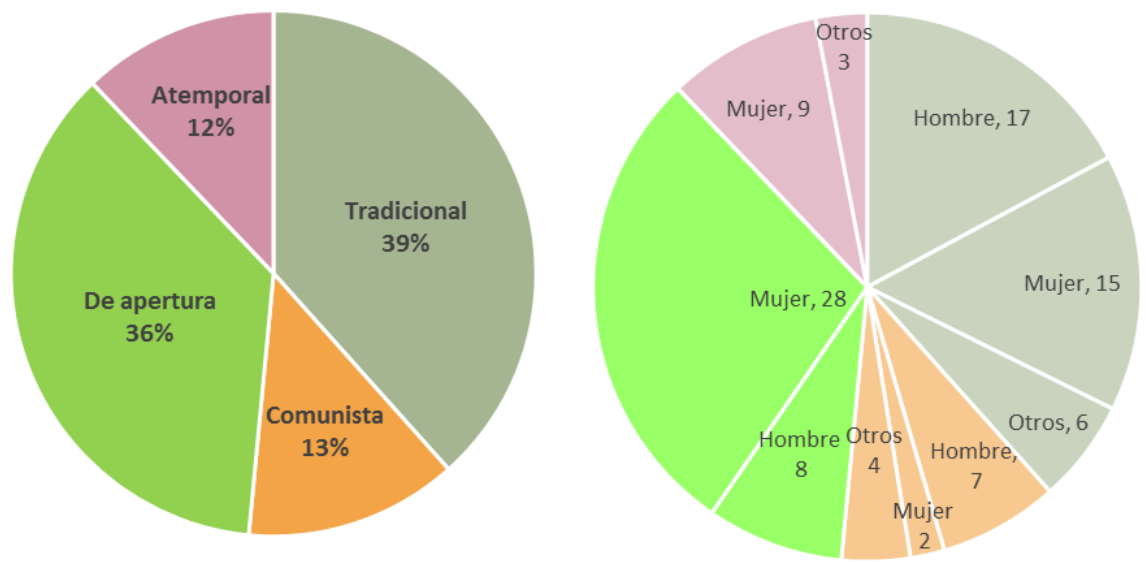


\subsection{MARCAS CULTURALES: LOS SINOGRAMAS}

Al ser uno de los símbolos de la cultura china, la escritura en caracteres constituye un elemento destacado como reclamo estético en las portadas de las novelas chinas, tanto como elemento principal como secundario. En este apartado, profundizamos en las 40 portadas que contienen sinogramas. En la figura 7 se observa que, a partir del siglo XXI, hay un flujo relativamente abundante del uso de este recurso, aunque podría ser que se deba a que en los últimos 20 años se han publicado más traducciones del chino al castellano y al catalán en España. Con el fin de interpretar la utilización de los sinogramas en las portadas, se ha analizado este elemento a través de dos categorías. La primera categoría se centra en los sinogramas que se usan solo en el título y/o en el nombre del autor, y la segunda en los que aparecen como parte de la imagen, o en otras palabras, como elemento estético de la portada.

Figura 7. Número de portadas con sinogramas por períodos ${ }^{7}$

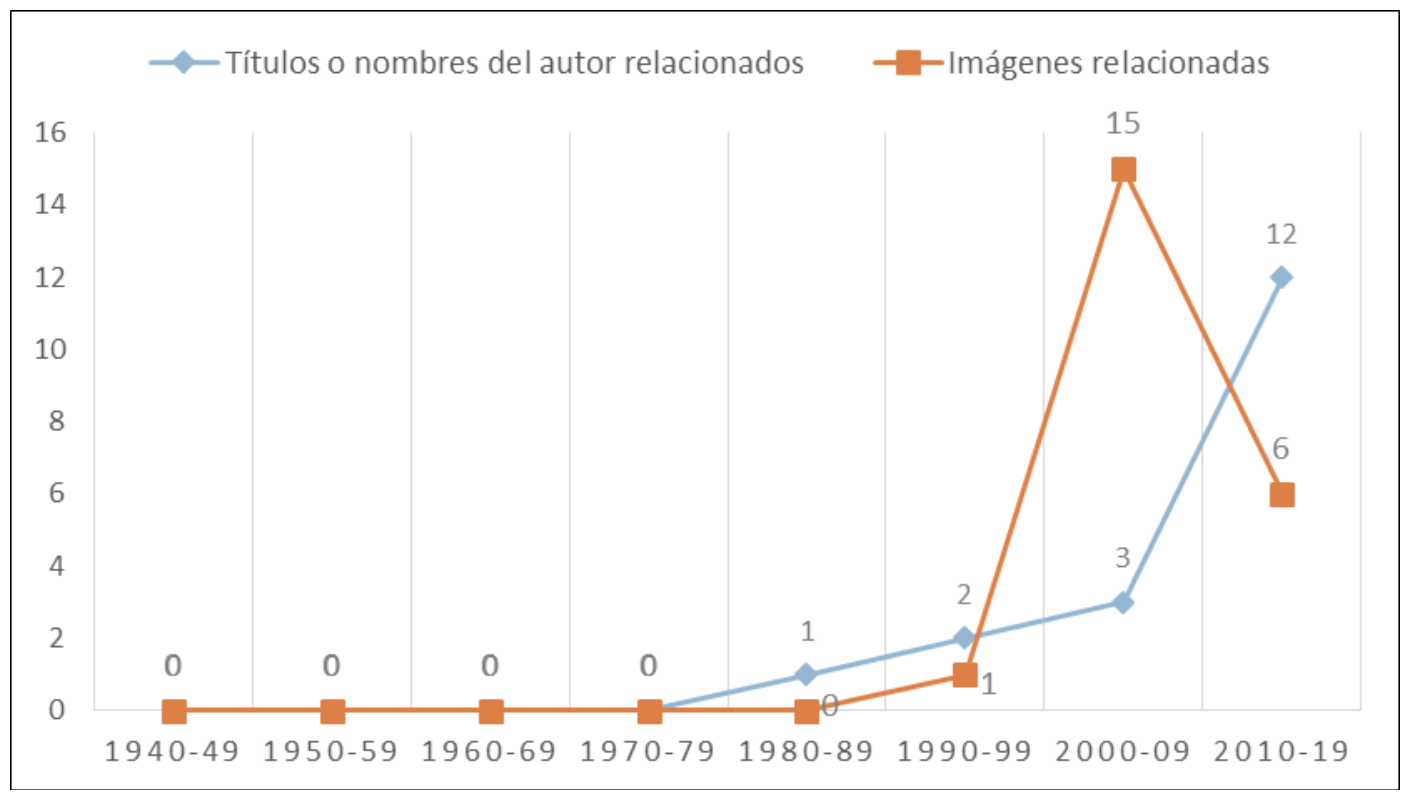

\subsubsection{Título y nombre del autor en sinogramas}

En nuestro corpus tenemos 18 portadas en las que, aparte de la lengua de llegada, también muestran el título y/o el nombre del autor en sinogramas. Entre ellas, destacamos dos casos específicos: Ocho escritoras chinas es la antología de relatos seleccionados de diferentes autoras, si bien no aparece el título original en chino, los caracteres en sinogramas corresponden a la traducción literal del título en castellano. Por otro lado, el título chino de El verano de la traición debería ser Luo Wu Dai (裸舞代) o Beipan zhi Xia (背叛之夏). Sin embargo, en su portada los caracteres que constan son Ji'e de Nü'er (飢餓的女兒), que corresponden a otra novela (La hija del rio, 2005) de la misma autora. No obstante, consideramos este caso más como un error de la editorial que a la intención deliberada de crear una imagen del Otro recurriendo a marcas culturales. En la tabla 2 se

\footnotetext{
${ }^{7}$ La muñeca de Pequín (2003) es la única traducción que cuenta con el título en sinogramas y contiene los elementos icónicos en la portada a la vez.
} 
muestran las obras con el título y/o el nombre del autor en sinogramas del año 1989 al 2019.

Tabla 2. Sinogramas de las portadas que corresponden al autor o título de la obra

\begin{tabular}{|c|c|c|c|}
\hline Año & Título & Nombre del autor & sexo \\
\hline 1989 & Hibisco (芙蓉镇) & Gu Hua (no) & M \\
\hline 1990 & Ocho escritoras chinas (中國女作家) & AA.VV. (no) & \\
\hline 1998 & El verano de la traición (飢餓的女兒) & Hong Ying (no) & $\mathrm{F}$ \\
\hline 2003 & La muñeca de Pequín (北京娃娃) & Chun Sue (no) & $\mathrm{F}$ \\
\hline 2007 & Las feroces aprendices Wang (no) & Bi Feiyu (毕飞宇) & M \\
\hline 2007 & Qingyi, ópera de la luna (no) & Bi Feiyu (毕飞宇) & M \\
\hline 2011 & Família (家) & Ba Jin (no) & M \\
\hline 2011 & Rana (蛙) & Mo Yan (no) & M \\
\hline 2013 & Nits fredes (寒夜) & Ba Jin (no) & M \\
\hline 2013 & La ciudad fronteriza (边城) & Shen Congwen (沈从文) & M \\
\hline 2014 & $\begin{array}{l}\text { El diario de la señorita Sofía- En el } \\
\text { hospital (莎菲女士的日記 在医院中) } \\
\text { La verdadera historia del camello }\end{array}$ & Ding Ling (丁玲) & $\mathrm{F}$ \\
\hline 2014 & $\begin{array}{l}\text { Xiangzi } \\
\text { (骆驼祥子) }\end{array}$ & Lao She (no) & M \\
\hline 2014 & El suplicio del aroma de sándalo (檀香刑 & Mo Yan (no) & M \\
\hline 2015 & Trece pasos (十三步) & Mo Yan (莫言) & M \\
\hline 2016 & Primavera (春) & Ba Jin (no) & M \\
\hline 2016 & El manglar (红树林) & Mo Yan (莫言) & M \\
\hline 2018 & $\begin{array}{l}\text { Campos de vida y muerte, y otros relatos } \\
\text { (生死场) }\end{array}$ & Xiao Hong (萧红) & $\mathrm{F}$ \\
\hline 2018 & $\begin{array}{l}\text { La primavera de Lan Caixia (藍彩霞的 } \\
\text { 春天) }\end{array}$ & Lee Chiao (李喬) & M \\
\hline
\end{tabular}


Jin

Figura 8. Ejemplos del uso de los sinogramas en el título en las obras de Ba
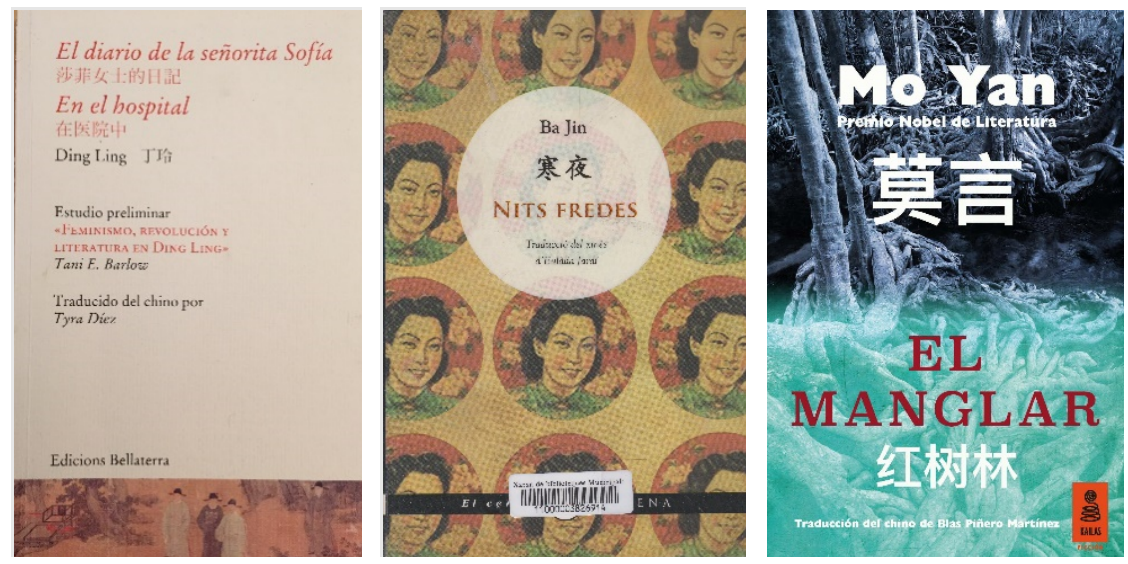

\subsubsection{El uso de los sinogramas en imágenes}

Aparte de analizar los títulos y los nombres del autor, también profundizamos en el uso de los sinogramas en las imágenes. En nuestro corpus, encontramos 22 portadas que contienen los sinogramas como elementos tanto principales como secundarios y las dividimos en tres tipos: los sinogramas que se relacionan con el contenido de la obra, los que no tienen relación con la obra y, por último, los casos especiales.

a) Sinogramas relacionados con el contenido de la obra

En primer lugar, tenemos cuatro imágenes de portadas que contienen sinogramas relacionados con el tema de la novela, tales como en Faltan palabras (2009), que muestra los caracteres zong qing ren (宗親人, varias generaciones de una familia). Del mismo modo, El profesor de inglés (2009) muestra varios registros del diccionario bilingüe del inglés al chino en su imagen. Este elemento encaja con lo que cuenta la novela, que empieza con un diccionario de inglés como sujeto protagonista. En el tercer caso tenemos Las feroces aprendices Wang (2007), en cuya portada aparece un cuadro panorámico de la puerta de Tian' anmen como fondo de la imagen. Ambos lados del retrato de Mao están adornados con los lemas Zhonghua Renmin Gongheguo wansui (中華人民共和國萬歲, viva la República Popular China) y shijie renmin datuanjie wansui (世界人民大團結萬 歲, viva la unidad de los pueblos del mundo), que son iguales a los que existen en la vida real en ese lugar. Debido a que la puerta, el perfil de Mao y los lemas han sido símbolos del comunismo desde la instauración de la República Popular China, creemos que estos sinogramas se relacionan con la historia que subraya la vida durante la Revolución Cultural.

Por último, La muñeca de Pekín (2003) es la única imagen que utiliza a la vez los sinogramas en el título y en la imagen. En la parte de arriba de la portada se observan muchos sinogramas pequeños y repetidos, estando algunos de ellos invertidos. Se pueden leer palabras relacionadas con la historia, tales como chuang (床, cama), shaokai (烧开, hervir), fangzi (房子, casa), jing xi jiao (京西郊, afueras al este de la capital, que podría referirse al barrio al este de Pekín donde ocurre la historia), pero el resto no se distingue mucho por la repetición. No obstante, esa repetición va más allá en su versión al catalán 
La nina de Pequín (2003), hasta no poder identificar ninguno de ellos. Por lo tanto, clasificamos La muñeca de Pekín (2003) en el grupo de sinogramas relacionados con la historia, mientras que La nina de Pequín (2003) se engloba en el grupo de los que no se relacionan con la historia.

Figura 9. Ejemplos de portadas en las que los sinogramas tienen relación con el contenido de la obra
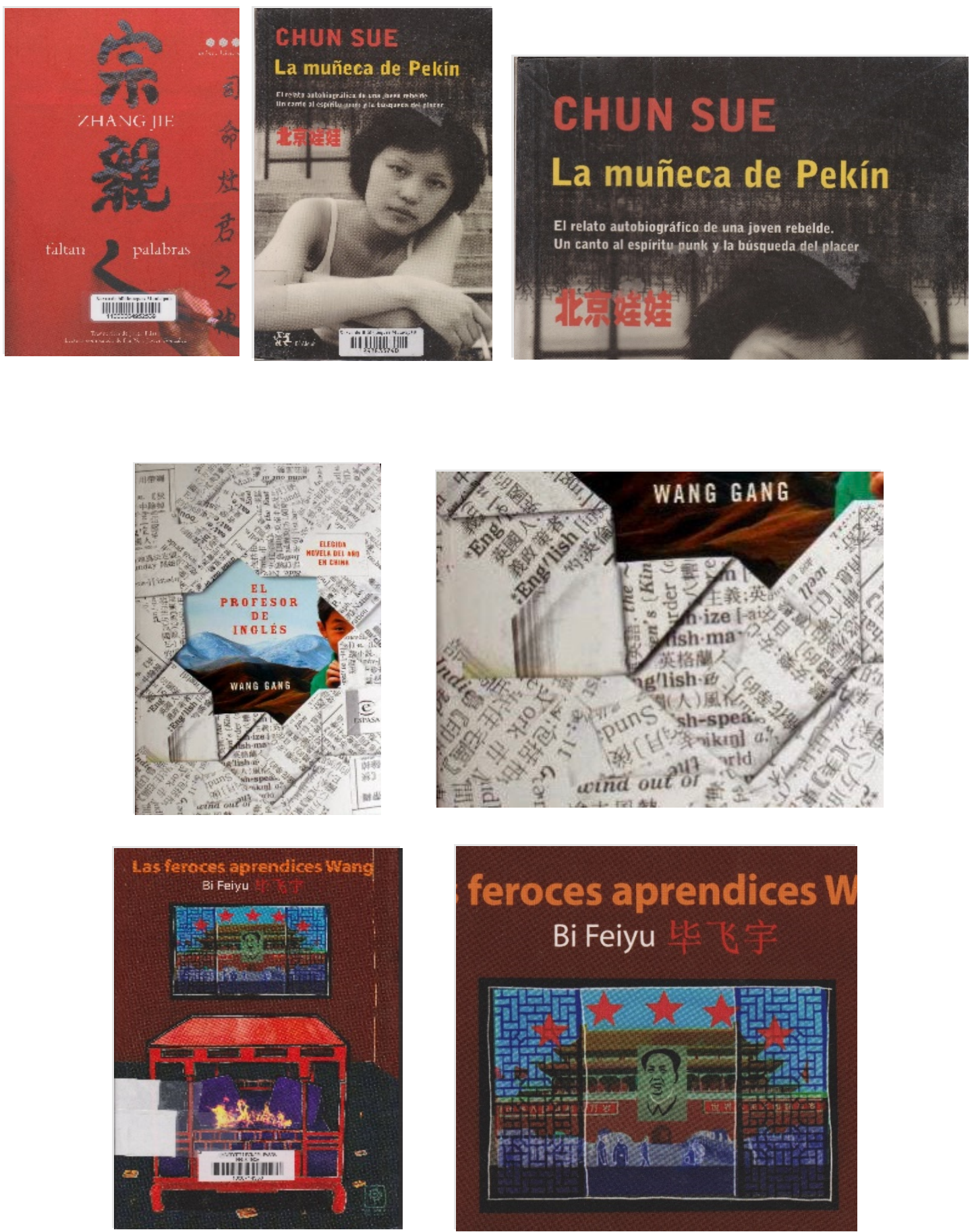

b) Sinogramas no relacionados con la obra

En la segunda categoría, tenemos 16 imágenes de portadas que contienen sinogramas no relacionados con el contenido de la obra. De ellas, Triste vida (2007), Trista vida 
(2007), Grandes pechos, amplias caderas (2007) y Olas (1990) utilizan los caracteres como elemento principal de la imagen. Triste vida (2007) y Trista vida (2007) comparten la misma imagen, pero con colores de fondo diferentes. Según la portada, identificamos el primer carácter cha (茶, té) y una parte del segundo que podría ser cualquier carácter con la clave shi (食, comer o comida). Sin embargo, no aparece ninguna palabra ni escena relacionadas con el té en la trama de la novela. Del mismo modo, en Grandes pechos, amplias caderas (2007) se muestra en la imagen los sinogramas nü (女, mujer) y dong ( 東, oriente), que juntos no tienen ningún sentido. En Olas (1990) se recurre a los sinogramas nü (女, mujer) y ren (人, persona) combinados de forma correcta, pero esta palabra tampoco está vinculada al contenido de la historia. En otras palabras, este tipo de desvinculaciones entre las obras y los caracteres presentados refuerza el estereotipo de antes de la imagen del "Otro" chino en España.

Figura 10. Ejemplos de portadas en las que los sinogramas de la portada no tienen relación con el contenido de la obra
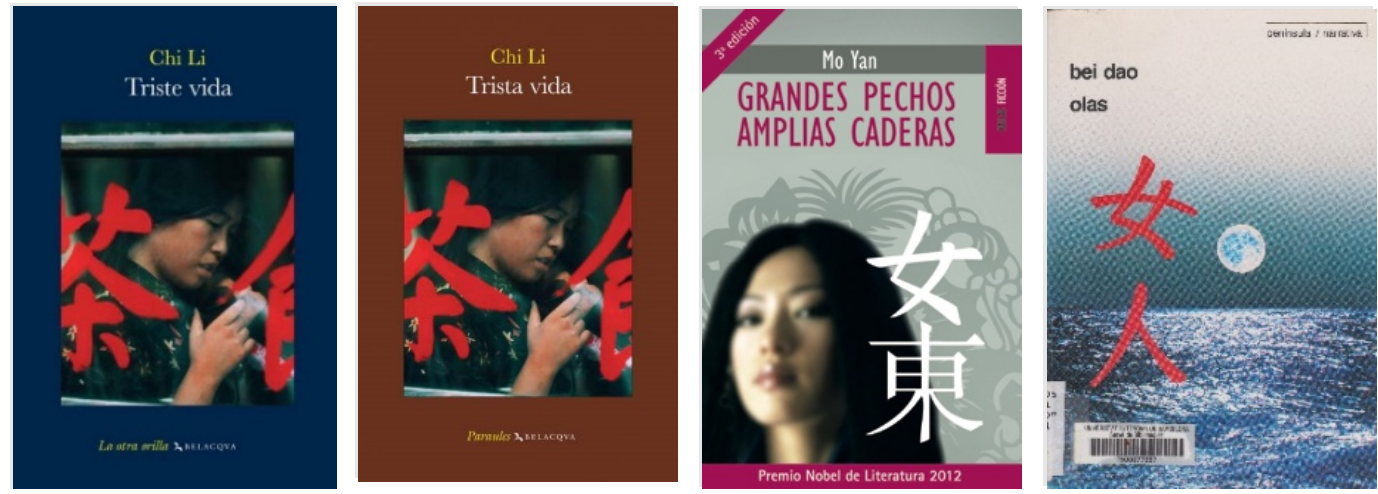

A continuación, tenemos 11 portadas que exponen sinogramas como elementos secundarios de la imagen que tampoco se relacionan con el contenido de la obra, que incluyen La nina de Pequín (2003), Aventuras y desventuras de un picaro chino (2004), Luna creciente: cuentos chinos contemporáneos (2007), Diari d'un boig i altres relats (2007), Pa pa pa (2008), Las baladas del ajo (2008), La ciudad de la reina (2009), La canción de la pena eterna (2010), La última princesa de Manchuria (2010), China en diez palabras (2013) y Una pizca de maldad (2018).

Por ejemplo, en las portadas de Luna creciente: cuentos chinos contemporáneos (2007) y de La última princesa de Manchuria (2010) se utilizan concretamente los sinogramas de gang (剛, duro o fuerte) y qingjie (情節, trama), respectivamente. Sin embargo, ninguno de ellos se relaciona con la historia. Asimismo, destacamos que Las baladas del ajo (2008) adopta un artículo periodístico sobre el problema de las débiles barracas ilegales de Hong Kong, como fondo de la imagen. Además, hemos encontrado un informe similar, que reproducimos en sinogramas a continuación, publicado en la página web oficial del gobierno de Hong Kong. ${ }^{8}$

${ }^{8}$ Página web oficial del gobierno de Hong Kong:

$<$ https://www.info.gov.hk/gia/general/201711/01/P2017110100452p.htm> [consultado en mayo de 2020] 
在一九八二年六月前已存在的寮屋, [...] 任何非法擴建或新建的寮屋, 均會被 即時拆除，有關人士也可遭檢控。[…] 任何人士非法佔用已由政府收回的寮屋 $[\ldots]$ 。

Según este documento, confirmamos que los sinogramas usados en Las baladas del ajo (2008) no están vinculados con la novela que escribió Mo Yan, inspirada en una historia real de los campos de ajo de la provincia china de Shandong. Otro caso sobre el uso de sinogramas de fondo de la imagen es La canción de la pena eterna (2010), que muestra un texto clásico del japonés antiguo en la portada. El texto proviene de la inscripción del monumento Meirinkan (明倫館碑), que es patrimonio cultural de Japón y se encuentra en la ciudad de Hagi (荻市).

Figura 11. Ejemplos de portadas en las que los sinogramas del fondo no tienen relación con el contenido de la obra
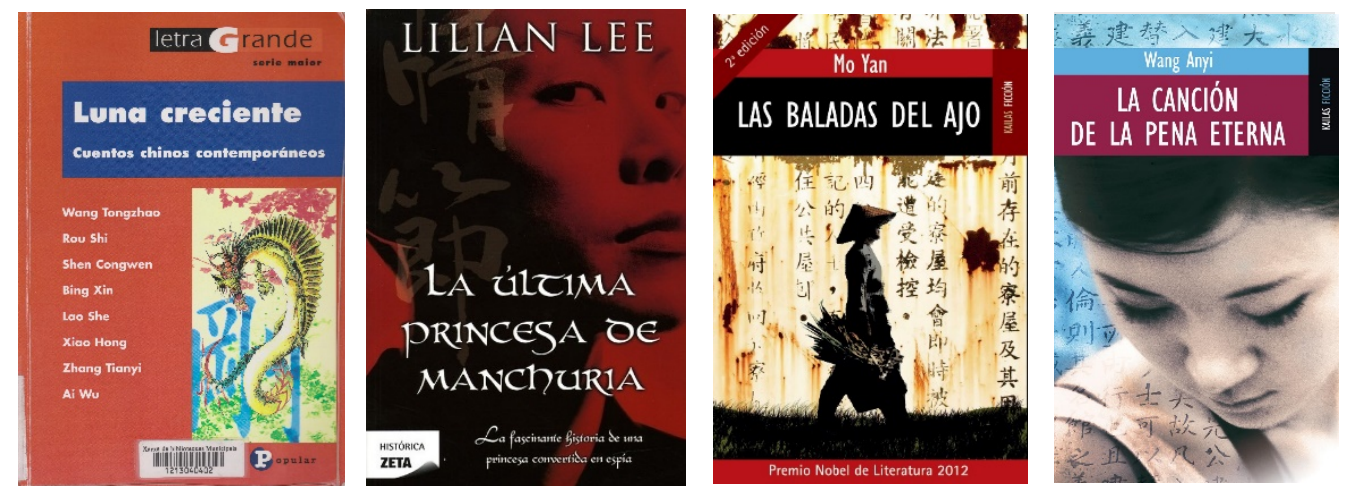

c) Casos especiales

En nuestro corpus, tenemos tres portadas con casos especiales, ilustradas en la figura 13. En primer lugar, China en diez palabras (2013) expone tres tipos diferentes de escritura. Principalmente se presentan diez palabras en castellano y sus correspondientes sinogramas en ortografía simplificada y tipografía estándar, que pertenecen al tema en la novela. Aparte de esas palabras, también hay sinogramas en caligrafía antigua y moderna en ortografía tradicional, que no están vinculados con la trama.

En segundo lugar, a pesar de que en la portada de Déjame en paz (2014) se muestran algunos caracteres en sinogramas formando palabras vinculadas íntimamente con la historia, tales como lüguan (旅館, hotel), xingbie (性別, sexo), jiyuan (妓院, prostíbulo), jiu (酒, alcohol) y kai (開, abrir). Sin embargo, también confirmamos que hay palabras o expresiones incompletas no relacionadas con el tema, por ejemplo, baishen yong (拜神 用, para rendir a Dios), weicheng (為城, siendo una ciudad), zhengzong (正宗, auténtico) y $f u$ (福, buena suerte). Es decir, no encontramos una coherencia del uso de los sinogramas en estas dos obras debido a que algunas palabras sí que están relacionadas con la historia, pero también las hay que se toman como marca cultural para construir la imagen del Otro chino.

Como último caso, en la portada de Casada con Buda (2005) no se distinguen mucho los caracteres de la imagen, debido a que están escritos en el cuerpo de la mujer y no parecen chino. Teniendo esto en cuenta, tampoco podemos asegurar que el libro que aparece como almohada esté escrito en sinogramas. Por otro lado, ponemos de relieve 
que Casada con Buda (2005) ha adoptado la imagen en la película "The Pillow Book" (1996) como portada. Esta película es la adaptación de la colección de prosa El libro de la almohada (1001) de la autora japonesa Sei Shonagon. Este fenómeno de confusión cultural también se ha documentado en La canción de la pena eterna (2010) y en el caso de la literatura japonesa, ya que en la portada de El pabellón del oro (1986) de Yukio Mishima aparece la imagen del Templo del Cielo de China en vez del Templo del Pabellón de Oro de Japón (Serra-Vilella, 2016). En otras palabras, el intercambio de símbolos culturales podría ser un ejemplo de la construcción de la imagen del "Otro" de Asia Oriental en Occidente. Debido a que Occidente, según Said ([1979] 2008), siempre interpreta y define Oriente con sus propias imaginaciones, sin precisar su perfil en realidad, sino que solo los identifican como "el Otro" para que se diferencie de "nosotros". En este sentido, Occidente agrupa todo Asia Oriental en una misma imagen, la de "ellos" y forma el estereotipo del "Otro".

Figura 12. Ejemplos de uso especial de los sinogramas en las portadas
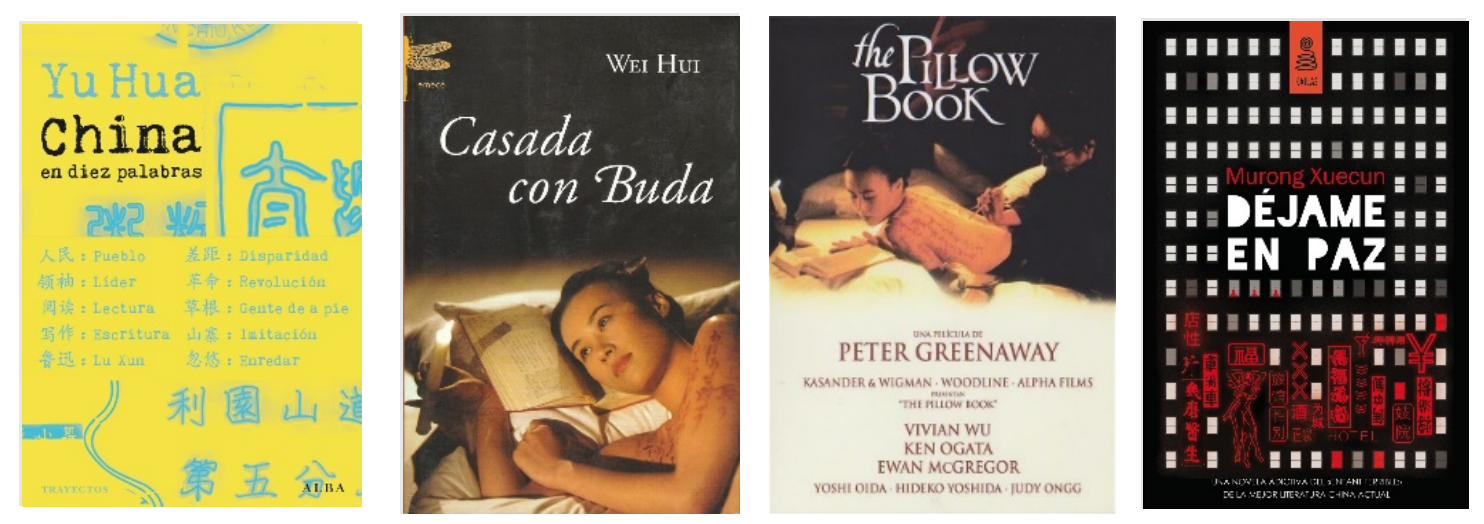

Según la figura 13, apreciamos que cuando los sinogramas no sirven para indicar la información del título o el nombre del autor, sino que funcionan como elementos icónicos en las portadas, se convierten en una herramienta valiosa para construir la imagen del Otro. De las 22 portadas que contienen sinogramas en la imagen, encontramos un $68 \%$ que no están relacionadas con el contenido de la obra. Asimismo, se usa como marca cultural para reforzar el carácter exótico de la cultura china en la sociedad española. Por otro lado, solo un $18 \%$ de los sinogramas usados concuerdan con la historia y un $14 \%$ poseen un uso ambiguo.

Figura 13. Usos de los sinogramas en imágenes

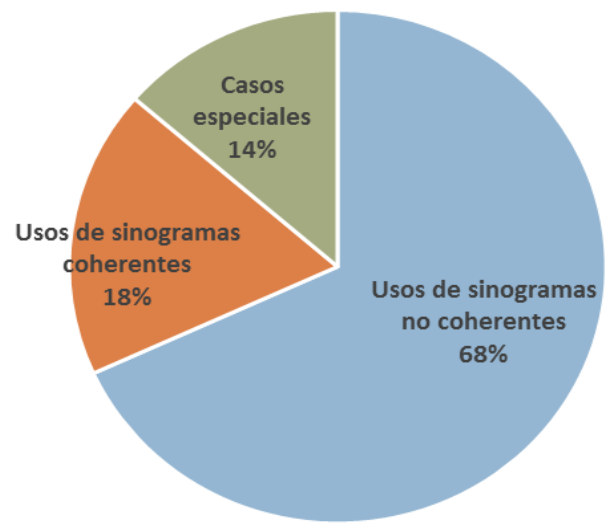




\section{CONCLUSIONES}

Según los tres enfoques que examinamos en este trabajo, los resultados de nuestro análisis revelan que las traducciones de la narrativa china contemporánea que se publicaron en castellano y en catalán en España (1949-2019) sirven como instrumento para producir y reforzar la imagen del Otro chino a los lectores españoles.

En primer lugar, de las 197 portadas recopiladas en nuestro corpus, encontramos que un $74 \%$ de ellas ha mostrado un ambiente temporal en concreto, repartido entre la época tradicional, la comunista y la de apertura. Sin embargo, de dicho $74 \%$, hay un $32 \%$ de las portadas que no mantienen la coherencia con la época que cuenta su contenido (véase la figura 2). Además, esta discordancia se refleja mayoritariamente en las portadas del período tradicional, debido a que la mitad de ellas no coinciden con su historia. Es decir, de las 197 portadas, hay un $20 \%$ de publicaciones que no tratan de la época tradicional, pero en cuyas portadas se presenta una imagen antigua de la cultura china.

En segundo lugar, de las 133 obras que fueron traducidas al castellano y /o al catalán, las que cuentan la historia del período comunista ocupan un $70 \%$, correspondiendo a 93 obras. Según este resultado, advertimos claramente esta preferencia de las editoriales españolas por introducir la literatura china contemporánea a los lectores españoles. Teniendo en cuenta que las 133 obras se volvieron a traducir y publicar varias veces hasta llegar a un total de 197 ediciones, el porcentaje de las ediciones vinculadas con la época comunista se ha reducido a un $40 \%$ en el conjunto del corpus. A pesar de que ha disminuido mucho el número de obras de la época comunista en España a lo largo del tiempo, el trasfondo comunista tampoco se refleja tanto en las portadas, ya que ocupa solo un $9 \%$ de la totalidad. Además, las portadas de la época tradicional y de la de apertura siguen alcanzando la mayoría con un $39 \%$ y un $26 \%$, respectivamente.

En cuanto al análisis del sexo, apreciamos que las editoriales pretenden escoger a las mujeres como imagen representante de los chinos, llegando hasta un 55\%, más de la mitad. Este resultado coincide con lo que propuso Said ([1979] 2008: 21), en el sentido de que el perfil de Oriente nunca fue bien comprendido, sino que fue definido como lo exótico y contrario a Occidente, situando en una posición inferior y representado por la imagen femenina.

Del mismo modo, el uso de los sinogramas también constituye un recurso estilístico que fortalece lo exótico de la cultura china. A pesar de que los sinogramas transmiten correctamente la información del título y/o el nombre del autor, cuando forman parte de la imagen de portada, se convierten en una marca cultural usada para crear la imagen del Otro en el proceso de la paratraducción, ya que en muchos casos no guardan relación con la trama de las obras.

En resumen, según los resultados de nuestro análisis, hemos corroborado que la traducción de las portadas ha desempeñado un papel importante en el cometido de crear una imagen del Otro chino en la sociedad española, ya que casi un tercio de ellas muestra una discordancia entre la imagen de la portada y el contenido de la historia. La imagen de los chinos está estancada a propósito en la época tradicional, reforzando esta imagen del Otro chino a los lectores españoles. Por otro lado, aunque tenemos un $26 \%$ de las portadas que trazan un perfil moderno de los chinos, un $9 \%$ de ellas no concuerdan con lo que cuenta la historia. Además, de las 197 portadas, casi no podemos encontrar trazas de la época comunista, a pesar de que esta temática subyace en la mayoría de obras introducidas a España. Dicho en otro modo, las portadas de las traducciones de la narrativa china contemporánea que se publicaron en España no solo forman una herramienta valiosa para crear la imagen del Otro chino, sino que, además la determinan estancada con un perfil 
tradicional. En definitiva, en este proceso, hemos confirmado que los agentes mediadores han desplegado su ideología y manipulado la imagen de China para que se acercara más a las expectativas de los lectores receptores, dejando de transmitir el perfil real de los chinos.

\section{REFERENCIAS BIBLIOGRÁFICAS}

Alvarado, Maite. 1994. Paratexto. Buenos Aires: Universidad de Buenos Aires.

Bell, Pholip. 2000. «Content Analysis of Visual Images». Handbook of Visual Analysis, eds. Theo van Leeuwen \& Carey Jewitt. London: Sage Publication.

Beller, Manfred y Joseph Theodoor Leerssen. 2007. Imagology: The Cultural Construction and Literary Representation of National Characters. A critical survey. Amsterdam: Rodopi.

Carbonell, Ovidi. 2004. «Vislumbres de la otredad. Hacia un marco general de la construcción semiótica del Otro en traducción». Vasos Comunicantes, 28: 59-71.

Eco, Umberto. 1984. The Role of the Reader: Explorations in the Semiotics of Texts. Bloomington: Indiana University Press.

Fernandes, Lincoln Paulo. 2006. «Corpora in Translation Studies: revisiting Baker's Tipology». Fragmentos: Revista de Lingua e Literatura Estrangeiras, 30: 87-95.

Genette, Gérard. 1997. Paratexts: Thresholds of interpretation. New York: Cambridge University Press.

Kovala, Urpo. 1996. «Translations, paratextual mediation, and ideological closure». Target. International Journal of Translation Studies, 8.1: 119-147.

Marin-Lacarta, Maialen. 2012. Mediación, recepción y marginalidad: Las traducciones de literatura china moderna y contemporánea en España [tesis doctoral]. Universitat Autònoma de Barcelona.

Said, Edward W. 1979. Orientalism. New York: Vintage.

Said, Edward W. 2008. Orientalismo. Trad. María Luisa Fuentes. Madrid: Debolsillo.

Serra-Vilella, Alba. 2016. La traducció de llibres japonesos a Espanya (1900-2014) i el paper dels paratextos en la creació de L'alteritat [tesis doctoral]. Universitat Autònoma de Barcelona.

Serra-Vilella, Alba. 2018. "The Other reflected in book covers: Japanese novel translations in Spain». Cultura, Lenguaje y Representación, vol. XIX: 141-161.

Shih, Shu-Mei. 2004. "Global literature and the technologies of recognition». PMLA, 119.1: 16-30.

Shih, Shu-Mei. 2011. «The Concept of the Sinophone». PMLA, 126. 31: 709-718.

Soenen, Jojan. 1992. «Imagology and Translation». Linguistica Antverpiensia, XXVI: $127-139$.

Venuti, Lawrence. 1988. The Scandals of Translation: Towards an Ethics of Difference. London \& New York: Routledge.

Yuste Frías, José. 2005. «Desconstrucción, traducción y paratraducción en la era digital». Estudios sobre traducción: teoría, didáctica, profesión, eds. José Yuste Frías y Alberto Álvarez Lugrís. Vigo: Servizo de Publicacións da Universidade de Vigo. 